\title{
Outcrossing rate and self-incompatibility in the colonizing species Senecio squalidus
}

\author{
RICHARD J. ABBOTT \& DAVID G. FORBES \\ Division of Environmental and Evolutionary Biology, School of Biological and Medical Sciences, University of St. Andrews, St. Andrews, \\ Fife KY16 9TH, U.K.
}

Levels of outcrossing and self-compatibility were estimated in two populations of Senecio squalidus, a highly successful colonizing species in the U.K. In both populations there was a tendency for outcrossing rate, $t$, to be depressed below unity in early summer; however, in neither instance was the departure from unity significant. Samples collected in early autumn also exhibited outcrossing rates not significantly different from $t=1$. Levels of self-compatibility measured in terms of seed set on selfing, were very low in all material tested. This finding plus the results of a crossing programme, provides evidence that British $S$. squalidus possesses a highly effective selfincompatibility system, most probably of the homomorphic sporophytic type. It is concluded that mating normally occurs at random in British populations of $S$. squalidus, although some degree of biparental inbreeding may also occur. The latter would cause inbreeding coefficients to exceed zero as recorded in a number of populations previously studied. The ability of $S$. squalidus to colonize new sites without engaging in uniparental sexual or asexual reproduction is briefly discussed.

Keywords: colonization, Compositae, outcrossing rate, self-incompatibility, Senecio squalidus.

\section{Introduction}

An association in plants between colonizing success and uniparental reproduction has been noted frequently in the literature (see Barrett \& Richardson, 1986; Gray, 1986, for reviews). Uniparental reproduction by selfing or asexual reproduction provides obvious benefits to a colonist allowing it to reproduce when mates are absent or at low density, as is often the case during the initial stages of colonization. Not all successful colonizing plants, however, appear capable of uniparental reproduction and as Barrett \& Richardson (1986) have pointed out, for successful outbreeding invaders it is necessary '. . . to examine how they overcome the constraints imposed by the requirement for mates during colonization'. Very few studies of this problem have been conducted to date, apart from those by Barrett et al. on heterostylous species (Glover \& Barrett, 1986; Barrett \& Shore, 1987; Barrett et al., 1989).

Senecio squalidus (Compositae), the Oxford ragwort, was introduced to the U.K. from Sicily, Italy, towards the end of the 17th century (Kent, 1956; Druce, 1927). It was subsequently cultivated in the Oxford Botanic Gardens, University of Oxford, from where it escaped to nearby walls and waste sites at the end of the 18th century. It has since spread rapidly through the British Isles, first as a colonizer of clinker and ballast of railways, and more latterly via the motorway system where it occurs frequently along roadside verges. In urban areas, it is a colonist of walls and waste sites. It is a short-lived perennial plant, reported to be self-incompatible (Gibbs et al., 1975) with no powers of clonal spread.

Two recent studies of allozyme variation in $S$. squalidus have shown that the average inbreeding coefficient within populations (Fis) was respectively, +0.217 and +0.243 at the Aat-3 and $\beta E s t-3$ loci (Abbott et al., 1992a,b). If this level of inbreeding were entirely the result of selfing, then the average selfing rate of $S$. squalidus would fall between 36 per cent to 39 per cent which is unexpectedly high for a 'selfincompatible' species. It is feasible that the high inbreeding coefficients recorded at the two isozyme loci may have stemmed from spatial substructuring within populations and biparental inbreeding rather than true selfing (Brown, 1990); nevertheless, the question is raised as to whether $S$. squalidus is fully self-incompatible.

Here we report an investigation aimed at: (i) estimating the rate of outcrossing in wild populations of $S$. squalidus during peak and late flowering periods, and 
(ii) determining the level of self-incompatibility in $S$. squalidus in terms of seed set on selfing.

\section{Materials and methods}

Seeds (cypselae) of Senecio squalidus were collected from a population in Oxford on 22 May and 22 September, 1991, and from a population in Edinburgh on 1 June and 1 October, 1991. Both populations occurred on waste sites. These populations were selected for study in view of possible differences between them with regard to level of self-compatibility and outcrossing rate. Whereas $S$. squalidus has been present in the wild in Oxford for the past 200 years, it only became established in the wild in Edinburgh during the 1950s (Kent, 1955). Before arriving in Edinburgh the species is likely to have repeatedly colonized new sites as it spread northwards through the U.K. During this process selection may have favoured an increase in level of self-compatibility relative to the material which remained in Oxford.

The population from which material was sampled in Edinburgh was large, consisting of several thousand individuals, whereas the Oxford population was much smaller, containing approximately 200 plants. Both populations were at their peak of flowering when first sampled, but had almost stopped flowering at the time of the second collection. At each sampling date seed was collected from between 25 and 40 plants per population, with collections from individual plants kept separate. Between 15 and 20 offspring per mother plant sampled from each population were raised from seed in a greenhouse in trays containing a peat-based compost. At the early juvenile stage, approximately 4-5 weeks from sowing, offspring were assayed for genotype at the Aat-3 locus using the electrophoretic and staining procedures described in Abbott et al. (1992a). The isozyme assay was limited to this locus as a preliminary survey showed that the $\beta E s t-3$ locus was virtually monomorphic in both populations. Progeny data were used to calculate maternal plant genotypes and single locus outcrossing rates, $t$, by the maximum likelihood procedures described in Ritland \& Jain (1981) using a modified version of the MLT computer program of Ritland (1990). The inbreeding coefficient of maternal plants, $F m$, was calculated as $F m=1-h o /$ $h e$, where ho and he are respectively, the frequencies of heterozygotes observed and expected under random mating. Feq, the inbreeding coefficient at inbreeding equilibrium, was computed as $F e q=1-t / 1+t$ (Nei \& Syakudo, 1955).

Following electrophoresis, some plants raised from seed of the Oxford May sample were grown on to flowering for crossing and selfing. Using plants derived from 14 different families, 29 reciprocal crosses were made, and 28 individuals were selfed. For crossing, capitula were kept enclosed in bags made from lens tissue until most florets were open with stigmas unfurled and pollen presented. Reciprocal crosses were made by rubbing together the capitula of two selected parents before rebagging. Selfing was conducted by keeping capitula enclosed in bags until seed had set or ovules had aborted. Between one and four capitula were selfed per individual tested. In a similar way, 47 offspring raised from six maternal plants from the Edinburgh June sample were selfed to test for selfincompatibility. Approximately 4 weeks after bags were initially placed on capitula, and at a stage when seed formation or ovule abortion was complete, each capitulum was carefully removed from its bag and a record was taken of the number of seed set. For crossed capitula, the number of aborted ovules was also recorded to enable calculation of percentage seed set per capitulum.

\section{Results and discussion}

\section{Outcrossing}

In both the Oxford and Edinburgh populations sampled in May and June, respectively, there was an indication that some selfing had occurred, i.e. $t$ was less than 1. However, for neither of these two samples nor the Oxford September and Edinburgh October samples, was the outcrossing rate significantly different from unity (Table 1). In three of the four samples examined, chi-squared tests of the goodness of fit of the observed frequencies of progeny genotypes to those expected, based on the maternal genotype frequencies, $t$, and pollen allele frequencies, showed there was a good fit of the progeny data to the mixed mating model (Clegg, 1980; Brown et al., 1989) used to estimate $t$.

Despite the good fit of data to model assumptions, a further test was conducted of the assumed absence of subpopulation heterogeneity in allele frequency within each population sample. This was done by comparing the frequency of heterozygotes in progeny arrays of homozygous seed parents, using a $2 \times m$ contingency table, where $m=$ number of maternal parents of the most common homozygous genotype (Brown et al., 1975; Schoen, 1982). This test assumes that differences in the frequency of heterozygotes found in families of maternal plants is the result of heterogeneity in allele frequency among subpopulations and not to differences in selfing ability, e.g. self-compatibility. In both Oxford samples the heterogeneity in the frequency of detected outcrosses was significant (Oxford May: $\chi_{17}^{2}=34.85^{* *}$; Oxford September: 
Table 1 Outcrossing rates $(t)$, pollen and ovule allele frequencies $(p, o)$, inbreeding coefficients of maternal parents $(F m)$ and at inbreeding equilibrium $(F e q)$, and $\Delta F$ values for two populations of Senecio squalidus sampled on two dates in 1991

\begin{tabular}{|c|c|c|c|c|}
\hline \multirow[b]{2}{*}{ Population } & \multicolumn{2}{|l|}{ Oxford } & \multicolumn{2}{|l|}{ Edinburgh } \\
\hline & May (1991) & September (1991) & June (1991) & October (1991) \\
\hline Number of families & 29 & 23 & 30 & 29 \\
\hline $\begin{array}{l}\text { Number of individuals } \\
\text { Aat3- }\end{array}$ & 403 & 408 & 600 & 539 \\
\hline \multicolumn{5}{|l|}{ Aat3- } \\
\hline$p \quad 3 b$ & $0.185(0.059)$ & $0.184(0.046)$ & $0.567(0.026)$ & $0.552(0.027)$ \\
\hline $3 c$ & $0.815(0.059)$ & $0.816(0.046)$ & $0.433(0.026)$ & $0.448(0.027)$ \\
\hline$o \quad 3 b$ & $0.190(0.053)$ & $0.283(0.066)$ & $0.600(0.062)$ & $0.569(0.067)$ \\
\hline $3 c$ & $0.810(0.053)$ & $0.717(0.066)$ & $0.400(0.062)$ & $0.431(0.067)$ \\
\hline$t$ & $0.719(0.150)$ & $1.116(0.099)$ & $0.902(0.064)$ & $0.978(0.065)$ \\
\hline$\chi_{1}^{2}$ & 2.03 (n.s.) & $10.68^{* *}$ & 3.07 (n.s.) & 0.08 (n.s) \\
\hline Fm & $-0.234(0.069)$ & $0.035(0.224)$ & $-0.111(0.179)$ & $0.086(0.184)$ \\
\hline $\mathrm{Feq}$ & 0.163 & -0.052 & 0.051 & 0.011 \\
\hline$\Delta F$ & -0.397 & 0.088 & -0.179 & 0.075 \\
\hline
\end{tabular}

S.E. in parentheses.

Note: standard errors for $p, o$ and $t$ were calculated using the MLT program of Ritland (1991) with 500 bootstraps. S.E.s of Fm were calculated using the equation in Brown $(1979) . \chi_{(1)}^{2}$ values are for tests of goodness of fit of observed progeny data to that expected based on the mixed mating model.

$\left.\chi_{11}^{2}=23.02^{*}\right)$, indicating the presence of significant subpopulation heterogeneity in allele frequency in the Oxford population. In contrast, for neither sample from the Edinburgh population was the chi-squared value significant.

In both the Oxford May and Edinburgh June samples, the frequency of heterozygotes among the population of maternal plants was greater than expected at Hardy-Weinberg equilibrium, causing inbreeding coefficients, $F m$, to be negative (Table 1). However, in the later samples from these two populations estimates of $\mathrm{Fm}$ were very close to zero as would be expected with panmixia. This difference between early and late samples might stem from a tendency for heterozygotes at the Aat-3 locus to produce seed in advance of homozygotes, possibly placing them at an advantage during colonization of a new site. In both the Oxford May and Edinburgh June samples, $\Delta F$ values $(\Delta F=F m-F e q)$ were negative as expected when heterozygotes are at an advantage (Brown, 1979).

\section{Self-incompatibility}

Of 51 capitula that were selfed on plants derived from the Oxford May sample, 45 capitula produced no seed, four produced one seed per capitulum, and the remaining capitula produced two and four seed, respectively. Similarly, in material derived from the Edinburgh sample, 69 of 76 selfed capitula failed to set seed, four capitula set one seed per capitulum, two yielded two seed each, and one capitulum set five seed. Means for number of seed set per selfed capitulum were very low in both samples (Table 2). It is concluded that British Senecio squalidus possesses a strong self-incompatibility (SI) mechanism. The possibility that selfing may be increased by assisted pollination, i.e. rubbing together different capitula from the same plant rather than leaving them undisturbed in bags, was investigated in another study (Wilson, 1991), but was found not to have an effect.

Of 29 reciprocal crosses made between plants derived from different maternal plants of the Oxford May sample, 18 showed reciprocal compatibility, nine exhibited reciprocal incompatibility, and two crosses were compatible in one direction but not the other, i.e. they displayed a reciprocal difference in compatibility. Crosses were considered as incompatible when seed set per capitulum was below 10 per cent. Mean percentage seed set per capitulum for the reciprocally compatible crosses was $69.32 \pm 8.45$ per cent, and for the reciprocally incompatible crosses was $1.78 \pm 1.60$ per cent (Table 2). The occurrence of reciprocal differences in cross-compatibility between some pairs of parent plants is a feature of sporophytic SI (Lewis, 1979) as is the production of trinucleate pollen and inhibition of pollen at the stigma surface, both of which occur in $S$. squalidus (R. Ingram \& D. F. Marshall, personal communication). It seems, therefore, that $S$. squalidus possesses a homomorphic sporophytic SI system, as do other self-incompatible species of the Compositae that have been investigated (Gerstel, 1950; Hughes \& Babcock, 1950; Crowe, 1954). The fact that a fairly large pro- 
Table 2 Seed set per capitulum following crossing or selfing plants derived from the Oxford May sample, and following selfing plants of the Edinburgh June sample

\begin{tabular}{llll}
\hline Population & $\begin{array}{l}\text { Number of } \\
\text { capitula }\end{array}$ & $\begin{array}{l}\text { Number of seed/ } \\
\text { capitulum }\end{array}$ & $\begin{array}{l}\text { Seed set/ } \\
\text { capitulum (\%) }\end{array}$ \\
\hline $\begin{array}{l}\text { Oxford } \\
\text { Crosses (Reciprocally } \\
\text { compatible) }\end{array}$ & 36 & $74.08( \pm 4.67)$ & $69.32( \pm 4.16)$ \\
$\quad \begin{array}{l}\text { (Reciprocally } \\
\text { incompatible) }\end{array}$ & 18 & $1.72( \pm 0.77)$ & $1.78( \pm 0.76)$ \\
$\begin{array}{c}\text { Selfs } \\
\text { Edinburgh }\end{array}$ & 51 & $0.20( \pm 0.09)$ & - \\
$\quad$ Selfs & 76 & $0.17( \pm 0.08)$ & - \\
\hline
\end{tabular}

$95 \%$ confidence limits in parentheses.

portion of crosses was incompatible ( 34.5 per cent) would suggest that cross compatibility is constrained in the Oxford population by the presence of a low number of $S$ alleles. Given the population 'bottleneck' which the species is likely to have passed through during its introduction to the U.K., all British populations of $S$. squalidus may contain few $S$ alleles relative to numbers of $S$ alleles normally found in populations of other species that exhibit homomorphic sporophytic self-incompatibility (Karron et al., 1990). Future research should test this possibility.

\section{Conclusions}

The results of this study have demonstrated that Senecio squalidus in the U.K. possesses a strong selfincompatibility mechanism (most probably of the homomorphic sporophytic type), and that in the samples studied, the estimated outcrossing rate was not significantly different from $t=1$, i.e. the expected outcrossing rate with random mating. These findings raise two important questions. First, why have previous studies found that the average inbreeding coefficients recorded within populations at the $\beta E s t-3$ and $A a t-3$ loci were above +0.2 , indicating that some inbreeding occurs in at least some British populations of the species (Abbott et al., 1992a,b)? Second, how has S. squalidus become such a successful colonizing species in the U.K. when its self-incompatibility system is expected to prevent uniparental sexual reproduction from taking place?

An answer to the first question may be that in many populations of the species some degree of biparental inbreeding occurs. Biparental inbreeding in outbreeding plant species, caused by assortative movements by pollinators and/or mating between neighbours which are closely related, is frequently held responsible for depressing values of $t$ below $t=1$ (Ennos \& Clegg,
1982; Uyenoyama, 1986) and raising, therefore, the inbreeding coefficient within populations above zero. In the present study there was evidence of significant subpopulation heterogeneity in allele frequency at the Aat-3 locus within the Oxford population. This could have promoted some biparental inbreeding and in the May sample caused $t$ to be depressed below 1 (although not significantly so).

A possible answer to the second question may stem from the fact that $S$. squalidus is a short-lived perennial and as such will frequently survive to flower in more than 1 year following arrival at a new site. Thus a new population of colonizing individuals could expand in numbers and become established via seed immigration over 2 years or more before engaging in successful sexual reproduction. During this period a sufficient number of $S$ alleles (minimum of four in the absence of dominance) would need to accumulate in the population before at least some crosses became compatible.

Although the results of this study would indicate that $S$. squalidus possesses a strong sporophytic SI system, it cannot be ruled out that under certain field conditions the effectiveness of this system will be weakened resulting in an increase in level of self-compatibility. Studies on the homomorphic sporophytic SI system in Brassica (Cruciferae) have shown that increases in temperature, relative humidity and $\mathrm{CO}_{2}$ concentration frequently weaken the SI response causing self-fertilization to occur (Hodgkin et al., 1988). In the only other published study of selfcompatibility in S. squalidus, Gibbs et al. (1975) recorded percentage seed set on selfing to be $4.6 \mathrm{per}$ cent, which is considerably higher than the values recorded in the present study. Clearly further investigations of the colonizing success of S. squalidus in the U.K. should investigate whether self-compatibility in the species varies with environment. If it does, then this 
would be a further important factor to consider in regard to the two questions raised above.

\section{Acknowledgements}

This study was supported by an NERC grant (GR3/ 7313A) to R.J.A. We are grateful to Christine Wilson for conducting preliminary work, to Dr Andrew Lack for providing seed of the Oxford September sample, and to Dr Kermit Ritland for a modified version of his MLT computer program.

\section{References}

ABBotT, R. J., ASHTON, P. A. AND FORBES, D. G. 1992a. Introgressive origin of the radiate groundsel, Senecio vulgaris L. var. hibernicus Syme; Aat-3 evidence. Heredity, 68, 425-435.

ABBOTT, R. J., IRWIN, J. A. AND ASHTON, P. A. 1992b. Genetic diversity for esterases in the recently evolved stabilized introgressant, Senecio vulgaris L. var. hibernicus Syme, and its parental taxa $S$. vulgaris L. var. vulgaris L. and $S$. squalidus L. Heredity, 68, 547-556.

BARRETT, S. C. H., MORGAN, M. T. AND HUSBAND, B. C. 1989. The dissolution of a complex genetic polymorphism: the evolution of self-fertilization in tristylous Eichhornia paniculata (Pontederiaceae). Evolution, 43, 1398-1416.

BARRETT, S. C. H. AND RICHARDSON, B. J. 1986. Genetic attributes of invading species. In: Groves, R. H. and Burdon, J. J. (eds), Ecology of Biological Invasions: An Australian Perspective. Aust. Acad. Sci. Canberra, pp. 21-33.

BARRETT, S. C. H. AND SHORE, J. S. 1987 . Variation and evolution of breeding systems in the Turnera ulmifolia L. complex (Turneraceae). Evolution, 41, 340-354.

BROWN, A. H. D. 1979. Enzyme polymorphisms in plant populations. Theor. Pop. Biol., 15, 1-42.

BROWN, A. H. D. 1990 . Genetic characterization of plant mating systems. In: Brown, A. H. D., Clegg, M. T., Kahler, A. L. and Weir, B. S. (eds), Plant Population Genetics, Breeding, and Genetic Resources, Sinauer, MA, pp. 145-162.

BROWN, A. H. D., BURDON, J. J. AND JOROSZ, A. M. 1989. Isozyme analysis of plant mating systems. In: Soltis, D. E. and Soltis, P. S. (eds), Isozymes in Plant Biology, Chapman and Hall, London, pp. 73-86.

BROWN, A. H. D., MATHESON, A. C. AND ELDRIDGE, K. G. 1975. Estimation of the mating system of Eucalyptus obliqua L'Herit. by using allozyme polymorphisms. Aust. J. Bot., 23, 931-949.

CLEGG, M. T. 1980. Measuring plant mating systems. Bioscience, 30, 814-818.

CROWE, L. 1954. Incompatibility in Cosmos bipinnatus. Heredity, 8, 1-11.
DRUCE, G. C. 1927. The Flora of Oxfordshire, 2nd edn. Clarendon Press, Oxford.

ENNOS, R. A. AND CLEGG, M. T. 1982. Effect of population substructuring on estimates of outcrossing in plant populations. Heredity, 48, 283-292.

GERSTEL, D. U. 1950. Self-incompatibility studies in Guayule. II. Inheritance. Genetics, 35, 482-506.

GiBBS, P. E., MILNE, C. AND VARGas CARRILlo, M. 1975. Correlation between the breeding system and recombination index in five species of Senecio. New Phytol., 75, 619-626.

GLOVER, D. E. AND BARRETT, s. C. H. 1986. Variation in the mating system of Eichhornia paniculata (Spreng.) Solms. (Pontederiaceae). Evolution, 40, 1122-1131.

GRAY, A. J. 1986. Do invading species have definable genetic characteristics? Phil. Trans. R. Soc. Lond. B, 314, 655-674.

HODGKIN, T., LYON, G. D. AND DICKINSON, H. G. 1988. Recognition in flowering plants: a comparison of the Brassica selfincompatibility system and plant pathogen interactions. New Phytol., 110, 557-569.

HUGHES, M. B. AND BABCOCK, E. B. 1950 . Self-incompatibility in Crepis foetida L. subsp. rhoedaifolia. Genetics, 35 , 570-588.

KARRON, J. D., MARSHALL, D. L. AND OlIVERAS, D. M. 1990. Numbers of sporophytic self-incompatibility alleles in populations of wild radish. Theor. Appl. Genet., 79, 457-460.

KENT, D. H. 1955. Scottish records of Senecio squalidus L. Proc. Bot. Soc. Brit. Is., 1, 312-313.

KENT, D. H. 1956. Senecio squalidus L. in the British Isles. I. Early records (to 1877). Proc. Bot. Soc. Brit. Is., 2, 115-118.

LEWIS, D. 1979. Sexual Incompatibility in Plants. Arnold, London.

NEI, M. AND SYAKUDO, K. 1955. The estimation of outcrossing in natural populations. Japan J. Genet., 33, 46-51.

RITLAND, K. 1990. A series of FORTRAN computer programs for estimating plant mating systems. J. Hered., 81, 235-237.

RITLAND, K. AND JAIN, S. 1981. A model for the estimation of outcrossing rate and gene frequencies using $n$ independent loci. Heredity, 47, 35-52.

SCHOEN, D. J. 1982. The breeding system of Gilia achilleifolia: variation in floral characteristics and outcrossing rate. Evolution, 36, 352-360.

UYENOYAMA, M. K. 1986. Inbreeding and the cost of meiosis: the evolution of selfing in populations practising biparental inbreeding. Evclution, 40, 388-404.

WILSON, c. 1991. Outcrossing in the Oxford Ragwort, Senecio squalidus. BSc. Hons. Thesis, University of St. Andrews. 